\title{
ATIVIDADE ORIENTADORA DE ENSINO: unidade entre ensino e aprendizagem
}

\section{Teaching guiding activity: unity between teaching and learning}

\section{Manoel Oriosvaldo de Moura ${ }^{[a]}$, Elaine Sampaio Araújo ${ }^{[b]}$, Vanessa Dias Moretti ${ }^{[c]}$, Maria Lúcia Panossian ${ }^{[d]}$, Flávia Dias Ribeiro ${ }^{[e]}$}

[a] Professor titular, docente da Faculdade de Educação da Universidade de São Paulo (0FE/USP), São Paulo, SP - Brasil, e-mail: modmoura@usp.br

[b]Docente do Departamento de Psicologia e Educação da Faculdade de Filosofia, Ciências e Letras de Ribeirão Preto - Universidade de São Paulo (FFCLRP/USP), Ribeirão Preto, SP-Brasil, e-mail:esaraujo@usp.br

[c]Docente do Departamento de Educação da Universidade Federal de São Paulo (UNIFESP), Guarulhos, SP - Brasil, e-mail: vanessa.moretti@unifesp.br

[d]Mestre em Educação pela Universidade de São Paulo (USP), professora efetiva da Rede Pública Estadual de SP - Brasil, e-mail: malupanossian@hotmail.com

[e Doutoranda em Educação pela Universidade de São Paulo (USP), docente da Faculdade Internacional de Curitiba (FACINTER), Curitiba, PR - Brasil, e-mail: flaviadr@usp.br

Rev. Diálogo Educ., Curitiba, v. 10, n. 29, p. 205-229, jan./abr. 2010 


\title{
Resumo
}

O artigo discute como o conceito de Atividade, compreendido como unidade de análise do desenvolvimento humano, pode fundamentar o trabalho do professor na organização do ensino, de acordo com os pressupostos teórico-metodológicos da psicologia histórico-cultural. Para isso, aborda os processos de apropriação da cultura humana e o papel do trabalho coletivo na constituição dos sujeitos, destacando a atividade de ensino como um modo de realização da educação escolar. Nesse sentido, o texto apresenta e discute as potencialidades do conceito de Atividade Orientadora de Ensino (AOE) que, ao ser planejada e desenvolvida a partir dos elementos da Atividade - necessidade, motivos, objetivos, ações e operações, possibilita o desenvolvimento do psiquismo dos sujeitos que a realizam. A qualidade de mediação da Atividade Orientadora de Ensino se evidencia ao possibilitar que o sujeito singular se aproprie da experiência humana genérica na direção do pensamento teórico.

Palavras-chave: Teoria histórico-cultural. Atividade. Pensamento teórico. Atividade orientadora de ensino. Aprendizagem.

\begin{abstract}
This article discusses how the concept of activity, understood as the unit of analysis of human development, can support the teacher's work in the organization of teaching, according to the theoretical and methodological assumptions of culturalhistorical psychology. For this purpose, it discusses the appropriation processes of human culture and the role of the collective work in the subject constitution, highlighting the teaching activity as an achievement way of school education. In this sense, the text presents and discusses the potential of the concept of Teaching Guiding Activity which, as it is planned and developed from elements of Activity - need, motive, objectives, actions and operations, enables the development of subjects' psychism in activity. The quality of mediation in the
\end{abstract}

Rev. Diálogo Educ., Curitiba, v. 10, n. 29, p. 205-229, jan./abr. 2010 
Teaching Guiding Activity is evidence when it allows the singular subject to take possession of the generic human experience toward theoretical thinking.

Keywords: Cultural-historical theory. Activity. Theoretical thinking. Teaching guiding activity. Learning.

Quais as possibilidades de a teoria, a partir das pesquisas que as sustentam, orientar as ações pedagógicas? Essa é uma pergunta que nos parece fundamental para aqueles que têm como atividade principal o ensino. Diante da complexidade dos fenômenos multifacetados que constituem a educação escolar, é necessário combater uma visão muitas vezes naturalizada, segundo a qual essa multiplicidade de fenômenos termina por levar o professor ou os responsáveis pela educação escolar a se aterem apenas aos fenômenos mais aparentes da educação escolar, tais como o pouco desempenho dos estudantes, a formação incipiente dos professores, a falta de motivação para o estudo, a indisciplina e a violência nas escolas.

Neste artigo abordaremos como o conceito de Atividade (LEONTIEV , 1978, 1983) pode fundamentar o trabalho do professor na organização do ensino. Trataremos, talvez, de um dos problemas menos aparente da ação pedagógica: a interdependência entre o conteúdo de ensino, as ações educativas e os sujeitos que fazem parte da atividade educativa. Com esta finalidade faremos uma breve retomada sobre os processos de apropriação da cultura humana e o papel do trabalho coletivo na constituição dos sujeitos. Em particular, trataremos da atividade de ensino como um modo de realização da educação escolar procurando evidenciar a semelhança desta atividade com os processos de formação das funções psíquicas superiores, que se dão na relação mediada por instrumentos culturais, dos sujeitos com os objetos.

A natureza particular da atividade de ensino, que é a máxima sofisticação humana inventada para possibilitar a inclusão dos novos membros de um agrupamento social em seu coletivo, dará a dimensão da responsabilidade dos que fazem a escola como espaço de aprendizagem e apropriação da cultura humana elaborada, bem como do modo de prover os indivíduos, metodologicamente de formas de

Rev. Diálogo Educ., Curitiba, v. 10, n. 29, p. 205-229, jan./abr. 2010 
apropriação e criação de ferramentas simbólicas para o desenvolvimento pleno de suas potencialidades.

Adiante, discutiremos, mais especificamente, as potencialidades da Atividade Orientadora de Ensino (AOE) (MOURA, 1996, 2001) como uma proposta de organização da atividade de ensino e de aprendizagem que, sustentada pelos pressupostos da teoria históricocultural, se apresenta como uma possibilidade de realizar a atividade educativa tendo por base o conhecimento produzido sobre os processos humanos de construção de conhecimento.

\section{Sobre o conceito e a aprendizagem}

A aprendizagem, conforme defende Vigotski (2002, p. 115), "[...] pressupõe uma natureza social específica e um processo através do qual as crianças penetram na vida intelectual daqueles que a cercam". É na relação do sujeito com o meio físico e social, mediada por instrumentos e signos (entre eles a linguagem), que se processa o seu desenvolvimento cognitivo. Ou seja, de acordo com o conceito de trabalho de Marx e Engels (1977), ao transformar a natureza o homem também se transforma.

Nessa perspectiva, o desenvolvimento psíquico do homem se realiza por meio do que Vigotski chamou de processo de internalização (VIGOTSKI, 2001). Segundo esse autor, as relações intrapsíquicas (atividade individual) constituem-se a partir das relações interpsíquicas (atividade coletiva). É neste movimento do social ao individual que se dá a apropriação de conceitos e significações, ou seja, dá-se a apropriação da experiência social da humanidade. Desta forma, podemos entender que a aprendizagem não ocorre espontaneamente e apenas a partir das condições biológicas do sujeito, mas mediada culturalmente. Nas palavras de Leontiev,

O homem não está evidentemente subtraído ao campo da ação das leis biológicas. O que é verdade é que as modificações biológicas hereditárias não determinam o desenvolvimento sócio-histórico do homem e da humanidade (LEONTIEV, 1978, p. 264).

Rev. Diálogo Educ., Curitiba, v. 10, n. 29, p. 205-229, jan./abr. 2010 
Essa compreensão sobre o desenvolvimento do psiquismo humano traz implicações para as relações entre o ensino e a aprendizagem e, mais especificamente, para a função da intencionalidade no processo educativo. Segundo Itelson (1979, p. 220),

resulta claro então que a assimilação de um sistema científico de conceitos e das conseqüentes estruturas da atividade psíquica, assim como o desenvolvimento multilateral e uniforme do aluno não são possíveis mediante somente a aprendizagem incidental baseado na atividade vital 'natural'. Para isso faz falta uma atividade especial, cuja finalidade básica é a própria aprendizagem. Essa atividade específica do homem que tem como fim direto a aprendizagem se chama estudo (tradução nossa).

Entre as décadas de 60 e 80, Davidov e outros pesquisadores russos realizaram pesquisas, por meio de reestruturação dos programas experimentais de estudo, que tinham a intenção de investigar as condições essenciais para dirigir o desenvolvimento psíquico dos escolares, bem como suas possibilidades intelectuais.

Ao considerar os pressupostos vigotskianos e da teoria da atividade, Davidov (1988, p. 76) dedicou-se à investigação da atividade de estudo dos escolares em diferentes níveis de ensino. Este pesquisador considera que "o ingresso na escola marca o começo de uma nova etapa de vida da criança, nela muito se modifica tanto no aspecto da organização externa quanto interna". O ingresso na escola marca, assim, um novo lugar que a criança ocupa no sistema das relações sociais. Davidov considera ainda que o ensino, desde as séries iniciais, deve garantir aos estudantes a apropriação teórica da realidade, sendo esta a essência da atividade de estudo. Assim, de acordo com os pressupostos de Leontiev, ele entende a atividade de estudo como a atividade dominante da criança em idade escolar.

A unidade fundamental da atividade de estudo para Davidov é a tarefa de estudo que tem por finalidade a transformação do próprio sujeito, transformação esta que não é possível fora das ações objetais que realiza. A compreensão das tarefas de estudo pelo estudante está associada à generalização teórica, sendo o conteúdo da atividade de

Rev. Diálogo Educ., Curitiba, v. 10, n. 29, p. 205-229, jan./abr. 2010 
estudo, as formas elevadas da consciência social - como a ciência, a arte e a ética - ou seja, o conhecimento teórico.

Assim, pois, o conteúdo principal da atividade de estudo é a assimilação dos procedimentos generalizados de ação na esfera dos conceitos científicos e mudanças qualitativas no desenvolvimento psíquico da criança, que ocorrem sobre esta base (DAVIDOV, 1987, p. 324).

Também compõem a atividade de estudo as ações de estudo. Para Davidov (1987), são as ações de estudo que permitem ao estudante ter condições de individualizar relações gerais, identificar ideias-chave da área de conhecimento, modelar relações, dominar procedimentos de passagem das relações gerais à sua concretização e vice-versa. $\mathrm{O}$ terceiro componente da atividade de estudo são as ações de autoavaliação e regulação. É por meio dessas ações que o estudante estará apto a avaliar suas próprias condições no início de seu trabalho, de seu percurso e dos resultados alcançados no decorrer da atividade.

Esses três componentes (tarefas de estudo, ações de estudo e ações de autoavaliação e regulação), trabalhados de forma integrada, e mediados pela ação do professor, permitem que o estudante se aproprie de conceitos historicamente construídos de forma sistematizada e intencional e se desenvolva intelectualmente com vistas ao pensamento teórico.

Assim, acredita-se que um dos elementos essenciais para o desenvolvimento de toda a potencialidade do sujeito se encontra na possibilidade de apropriação dos conhecimentos teóricos, que está representado nas inter-relações entre o interno e o externo, entre a totalidade e a aparência, entre o original e o derivado (DAVYDOV, 1982).

Para a formação do pensamento teórico do estudante, faz-se necessário organizar o ensino de modo que realize atividades adequadas para a formação desse pensamento. Davidov (1982) defende que é necessário partir das teses gerais da área do saber e não dos casos particulares, buscando a célula dos conceitos, sua gênese e essência ${ }^{1}$, o que se consegue por meio da operação de construir e transformar um

\footnotetext{
Por essência se entende "[...] conexões objetivas que em sua decomposição e manifestação asseguram a unidade de todos os aspectos do ser íntegro, ou seja, dotam o objeto de valor concreto." (DAVYDOV, 1988, p. 346).
}

Rev. Diálogo Educ., Curitiba, v. 10, n. 29, p. 205-229, jan./abr. 2010 
objeto mentalmente. Para o autor, o método que permite que se reproduzam teoricamente as formas de representação e contemplação sensorial, o concreto real, é o método de ascensão do abstrato ao concreto. As abstrações se alcançam por meio do desenvolvimento do objeto e permitem expressar a essência do objeto concreto. Já o concreto é o resultado mental da associação das abstrações e nele o objeto se apresenta em unidade com o todo. Assim, não se entende um conceito como uma abstração, ele é na verdade o concreto gerado a partir da associação de abstrações.

Desta forma, Davidov atenta para o método de ascensão do abstrato ao concreto, considerado um dos princípios didáticos necessários para uma organização do ensino que possibilite a formação do pensamento teórico.

A partir das contribuições de Davidov (1982), Rubtsov (1996), em seus estudos, considera a atividade de estudo como de aprendizagem. Em se tratando da definição dos termos (estudo e aprendizagem), figura importante salientar que, em alguns textos, sobretudo de tradução da língua russa para a língua inglesa, o termo atividade de aprendizagem é utilizado como equivalente ao de atividade de estudo. De acordo com o contexto educacional brasileiro, consideramos o termo atividade de aprendizagem mais apropriado e, assim, o utilizaremos como sinônimo de atividade de estudo ao longo deste texto, com o sentido de uma aprendizagem que decorre de uma atividade de ensino escolar, intencional, sistematizada e organizada, que objetiva a formação do pensamento teórico. De acordo com o conceito de atividade e considerando as particularidades do nosso contexto, estudo pode ser uma ação para a aprendizagem, enquanto que essa pode ser entendida como um estado ou processo do que se aprende.

Ao tratar da aprendizagem, Rubtsov o faz na perspectiva da atividade ressaltando o papel do coletivo na sua realização. Para o autor:

[...] as pesquisas dos psicólogos mostraram que a aptidão para a aprendizagem é, na verdade, resultado de uma determinada interiorização, de maneira que a atividade de aprendizagem se apresenta, essencialmente, sob a forma de uma atividade realizada em comum (RUBTSOV, 1996, p. 134).

Rev. Diálogo Educ., Curitiba, v. 10, n. 29, p. 205-229, jan./abr. 2010 
Desta forma, a atividade realizada em comum, coletiva, ancora o desenvolvimento das funções psíquicas superiores ao configurar-se no espaço entre a atividade interpsíquica e intrapsíquica dos sujeitos.

Ainda segundo Rubtsov, uma atividade pode ser caracterizada como atividade coletiva se contiver alguns dos seguintes elementos essenciais:

- a repartição das ações e das operações iniciais, segundo as condições da transformação comum do modelo construído no momento da atividade;

- a troca de modos de ação, determinada pela necessidade de introduzir diferentes modelos de ação, como meio de transformação comum do modelo;

- a compreensão mútua, permitindo obter uma relação entre, de um lado, a própria ação e seu resultado e, de outro, as ações de um dos participantes em relação a outro;

- a comunicação, assegurando a repartição, a troca e a compreensão mútua;

- o planejamento das ações individuais, levando em conta as ações dos parceiros com vistas a obter um resultado comum;

- a reflexão, permitindo ultrapassar os limites das ações individuais em relação ao esquema geral da atividade (assim, é graças à reflexão que se estabelece uma atitude crítica dos participantes com relação às suas ações, a fim de conseguir transformá-las, em função de seu conteúdo e da forma do trabalho em comum) (RUBTSOV, 1996, p. 136).

Essa sistematização de Rubtsov, acerca da atividade coletiva, permite-nos estabelecer relações entre a atividade de aprendizagem e a atividade de ensino ao fornecer indicadores sobre a organização do trabalho pedagógico, dos quais destacamos a comunicação e a repartição de ações com vistas à solução coletiva de um problema comum.

\section{Sobre o ensino}

Entender a escola como o lugar social privilegiado para a apropriação de conhecimentos produzidos historicamente passa necessariamente por assumir que a ação do professor deve estar organizada intencionalmente para esse fim.

Rev. Diálogo Educ., Curitiba, v. 10, n. 29, p. 205-229, jan./abr. 2010 
Embora o sujeito possa se apropriar dos mais diferentes elementos da cultura humana de modo não intencional, não abrangente e não sistemático, de acordo com suas próprias necessidades e interesses, é no processo de educação escolar que se dá a apropriação de conhecimentos aliada à questão da intencionalidade social, o que justifica a importância da organização do ensino, como aponta Moura (2002).

$\mathrm{Na}$ busca de organizar o ensino, recorrendo à articulação entre a teoria e a prática é que se constitui a atividade do professor, mais especificamente, a atividade de ensino. Essa atividade se constituirá como práxis pedagógica se permitir a transformação da realidade escolar por meio da transformação dos sujeitos, professores e alunos. Assim, é

[...] oscilando entre momentos de reflexão teórica e ação prática e complementando-os simultaneamente que o professor vai se constituindo como profissional por meio de seu trabalho docente, ou seja, da práxis pedagógica. Podemos dizer então que: se, dentro da perspectiva históricocultural, o homem se constitui pelo trabalho, entendendo este como uma atividade humana adequada a um fim e orientada por objetivos, então o professor constitui-se professor pelo seu trabalho - a atividade de ensino - ou seja, o professor constitui-se professor na atividade de ensino. Em particular, ao objetivar a sua necessidade de ensinar e, conseqüentemente, de organizar o ensino para favorecer a aprendizagem (MORETTI, 2007, p. 101).

A atividade de ensino do professor deve gerar e promover a atividade do estudante, deve criar nele um motivo especial para a sua atividade: estudar e aprender teoricamente sobre a realidade. É com essa intenção que o professor organiza a sua própria atividade e suas ações de orientação, organização e avaliação. Entretanto, considerando que a formação do pensamento teórico e da conduta cultural só é possível como resultado da própria atividade do homem, decorre que tão importante quanto a atividade de ensino do professor é a atividade de aprendizagem que o estudante desenvolve.

$O$ professor que se coloca, assim, em atividade de ensino continua se apropriando de conhecimentos teóricos que lhe permitem organizar ações que possibilitem ao estudante a apropriação de conhecimentos teóricos explicativos da realidade e o desenvolvimento

Rev. Diálogo Educ., Curitiba, v. 10, n. 29, p. 205-229, jan./abr. 2010 
do seu pensamento teórico, ou seja, ações que promovam a atividade de aprendizagem de seus alunos. Além disso, é um profissional envolvido também com a sua atividade de aprendizagem, atividade esta que o auxilia a tomar consciência de seu próprio trabalho e lidar melhor com as contradições e inconsistências do sistema educacional, na medida em que compreende tanto o papel da escola, dadas as condições sociais, políticas, econômicas, quanto o seu próprio papel na escola.

Tais ações do professor na organização do ensino concorrem para que a aprendizagem também ocorra de forma sistemática, intencional e organizada. Isso nos permite retomar a tese de Vigotski de que o 'bom ensino' é somente aquele que se adianta ao desenvolvimento, atuando na zona de desenvolvimento proximal. A esse respeito o autor afirma que:

[...] o aprendizado desperta vários processos internos de desenvolvimento, que são capazes de operar somente quando a criança interage com pessoas em seu ambiente e quando em cooperação com seus companheiros. Uma vez internalizados, esses processos tornam-se parte das aquisições do desenvolvimento independente da criança (VIGOTSKI, 2002, p. 117-118).

Nesse sentido, é possível compreender o papel fundamental do ensino no desenvolvimento das funções psíquicas superiores, no decorrer do processo de apropriação pelos estudantes de conceitos impregnados da experiência histórica. Sendo assim, a maneira pela qual o ensino está organizado intervém no desenvolvimento intelectual do sujeito, ou seja, "o ensino constitui a forma internamente indispensável e geral de desenvolvimento intelectual" (DAVIDOV, 1987, p. 180). Isso não significa que haja correspondência direta entre o ensino e o desenvolvimento do indivíduo, mas sim que o ensino é uma forma necessária e relevante para o desenvolvimento.

O ensino realizado nas escolas pelos professores deve ter a finalidade de aproximar os estudantes de um determinado conhecimento. Daí a importância de que os professores tenham compreensão sobre seu objeto de ensino, que deverá se transformar em objeto de aprendizagem para os estudantes. Além disso, é fundamental que no processo de ensino, o objeto a ser ensinado seja compreendido pelos estudantes como objeto de aprendizagem. Isso, para a teoria histórico-

Rev. Diálogo Educ., Curitiba, v. 10, n. 29, p. 205-229, jan./abr. 2010 
cultural, só e possível se este mesmo objeto se constituir como uma necessidade para eles. Assim, os conhecimentos teóricos são ao mesmo tempo objeto e necessidade na atividade de aprendizagem.

Uma vez que na estrutura do conceito de atividade (LEONTIEV, 1978, 1983) a necessidade se materializa no objeto, tornando-o o motivo da atividade, o mesmo se dá na atividade de aprendizagem. Sobre essa relação entre necessidade e motivo na atividade de aprendizagem, ou de estudo, como a denomina Davidov (1988, p. 178), este destaca que

[...] a necessidade da atividade de estudo estimula os escolares a assimilar os conhecimentos teóricos; os motivos, [estimula os escolares] a assimilar os procedimentos de reprodução destes conhecimentos por meio das ações de estudo, dirigidas a resolver as tarefas de estudos (recordamos que a tarefa é a unidade do objetivo da ação e as condições para alcançá-lo) (tradução nossa).

Como consequência, temos que algumas ações do ensino são mais eficazes no desenvolvimento do psiquismo dos sujeitos que outras. Logo, concordamos com Bogoyavlensky e Menchiskaya (2003, p. 48), quando afirmam que:

[...] para descobrir o que no desenvolvimento do conhecimento beneficia o desenvolvimento psíquico, é necessário conhecer como é assimilado o material escolar, ou seja, que operações de pensamento se usam.

Num processo de apropriação do conhecimento teórico, entendido como objeto da aprendizagem, estruturam-se as operações do pensamento teórico. Tais operações devem ser também o objeto da aprendizagem, tornado possível pela atividade de ensino, num movimento de análise e síntese que vai do geral ao particular, do abstrato ao concreto. Esta, ao desencadear a apropriação do conhecimento teórico, favorece a estruturação de um tipo particular de pensamento, o teórico. É importante, ainda, que as operações do pensamento (abstração, generalização e formação de conceitos) sejam desenvolvidas nos estudantes de diferentes faixas etárias. Nesse ponto, é primordial explicitar o que se entende por conceito, na perspectiva de Vigotski (1996, p. 81):

Rev. Diálogo Educ., Curitiba, v. 10, n. 29, p. 205-229, jan./abr. 2010 
É o reflexo objetivo das coisas em seus aspectos essenciais e diversos; se forma como resultado da elaboração racional das representações, como resultado de ter descoberto os nexos e as relações desse objeto com outros, incluindo em si, portanto, um amplo processo de pensamento e conhecimento que, dir-se-ia, está concentrado nele.

Entende-se, assim, que a aquisição de conceitos, desencadeada na atividade mediada, ocorre de forma sistematizada, intencional, e que o processo de aprendizagem deve garantir a realização de ações conscientes, de modo a possibilitar o desenvolvimento do pensamento teórico. O motivo da atividade de aprendizagem deve ser por parte dos estudantes a aquisição de conceitos teóricos, por meio de ações conscientes que permitam a construção de um modo generalizado de ação.

Para que a aprendizagem se concretize para os estudantes e se constitua efetivamente como atividade, a atuação do professor é fundamental ao mediar a relação dos estudantes com o objeto do conhecimento, orientando e organizando o ensino. As ações do professor na organização do ensino devem criar, no estudante, a necessidade do conceito, fazendo coincidir os motivos da atividade com o objeto de estudo. O professor, como aquele que concretiza objetivos sociais objetivados no currículo escolar, organiza o ensino: define ações, elege instrumentos e avalia o processo de ensino e aprendizagem. É com o intuito de apresentar uma possibilidade de realização do ensino fundamentado nos pressupostos teóricos que desenvolvemos anteriormente, que discutiremos o conceito de Atividade Orientadora de Ensino, proposto inicialmente por Moura (1996, 2001).

\section{A Atividade Orientadora de Ensino: unidade entre ensino e aprendizagem}

A complexidade da práxis pedagógica, pelo exposto até agora, evidencia a verdadeira dimensão da atividade de ensino. Nesta, estão presentes o conteúdo de aprendizagem, o sujeito que aprende, o professor que ensina e, o mais importante, a constituição de um modo geral de apropriação da cultura e do desenvolvimento do humano genérico.

Rev. Diálogo Educ., Curitiba, v. 10, n. 29, p. 205-229, jan./abr. 2010 
Para Leontiev (1994), o sujeito, durante seu desenvolvimento ontogenético, ocupa diferentes lugares no sistema das relações humanas relacionadas com a atividade principal - o jogo, o estudo e o trabalho - por meio da qual se reorganizam os processos psíquicos e ocorrem as principais mudanças psicológicas na personalidade.

Analisar o desenvolvimento do sujeito por meio da atividade principal é fundamental para compreender o papel da educação e da organização do ensino sobre a sua atividade e a formação da consciência.

Assim, compreender o conceito de atividade como unidade de análise do desenvolvimento humano e as principais relações que o caracterizam, pode orientar a organização do ensino. Segundo Moura (2002, p. 157), "tomar o ensino como uma atividade implica em definir o que se busca concretizar com a mesma, isto é, a atividade educativa tem por finalidade aproximar os sujeitos de um determinado conhecimento", no sentido de possibilitar a apropriação dos conhecimentos produzidos socialmente.

Sforni (2004, p. 95), em seus estudos a respeito da Teoria da Atividade indica que

pode-se inferir que o desenvolvimento psíquico da criança não é necessariamente desencadeado quando ela é formalmente ensinada ou fica estanque quando não é ensinada por um indivíduo em particular, mas quando passa a participar de uma atividade coletiva que lhe traz novas necessidades e exige dela novos modos de ação. É a sua inserção nessa atividade que abre a possibilidade de ocorrer um ensino realmente significativo.

O desafio que se apresenta ao professor relaciona-se com a organização do ensino de modo que o processo educativo escolar se constitua como atividade para aluno e professor. Para o aluno, como estudo e para o professor como trabalho. Com esse objetivo, Moura (1996) propõe o conceito de Atividade Orientadora de Ensino. A AOE mantém a estrutura de atividade proposta por Leontiev ao indicar uma necessidade (apropriação da cultura), um motivo real (apropriação do conhecimento historicamente acumulado), objetivos (ensinar e aprender) e propõe ações que considerem as condições objetivas da instituição escolar.

Cedro (2004), ao considerar tais elementos, caracteriza o que entende por 'espaços de aprendizagem', como forma de superar o 'encapsulamento' da aprendizagem escolar e viabilizar a AOE:

Rev. Diálogo Educ., Curitiba, v. 10, n. 29, p. 205-229, jan./abr. 2010 
Para fundamentar uma organização do ensino que possa superar o 'encapsulamento' da aprendizagem escolar, redefiniremos e utilizaremos o termo espaço de aprendizagem como o lugar da realização da aprendizagem dos sujeitos orientados pela ação intencional de quem ensina (CEDRO, 2004, p. 47 , grifos do autor).

Considerando, então, que um ensino que promova a aprendizagem pressupõe o sujeito em atividade que lhe permita compartilhar significados, num contexto de 'espaços de aprendizagem', no qual a ação de quem ensina é fundamental, destaca-se a Atividade Orientadora de Ensino como o núcleo do trabalho do profissional do ensino, no caso o professor, no processo de ensino e aprendizagem.

A partir da estrutura da Atividade (LEONTIEV, 1978, 1983), torna-se possível identificar alguns elementos do conceito de Atividade na Atividade Orientadora de Ensino, na qual a necessidade do professor é a de ensinar e a do aluno é aprender. O que é objetivado na AOE de ensino é a transformação do psiquismo do sujeito que está em atividade de aprendizagem. Nesse sentido, podemos compreender que o estudante, ao apropriar-se dos conhecimentos objetivados no currículo escolar, é também objeto na atividade de ensino do professor (KUZMINA, 1987). No conceito de atividade, o objeto é aquilo que coincide com o motivo da atividade e é objetivado no processo de trabalho, o estudante transformado é também produto do trabalho do professor.

$\mathrm{Na}$ AOE, ambos, professor e aluno, são sujeitos em atividade e como sujeitos se constituem como indivíduos portadores de conhecimentos, valores e afetividade que estarão presentes no modo como realizarão as ações que têm por objetivo um conhecimento de qualidade nova. Tomar consciência de que sujeitos em atividade são indivíduos é primordial para considerar a Atividade Orientadora de Ensino como um processo de aproximação constante do objeto: o conhecimento de qualidade nova. A atividade, assim, só pode ser orientadora. Nesse sentido, a AOE toma a dimensão de mediação ao se constituir como um modo de realização de ensino e de aprendizagem dos sujeitos que, ao agirem num espaço de aprendizagem, se modificam e assim também se constituirão em sujeitos de qualidade nova.

Desse modo, as ações do professor devem ser organizadas de forma a possibilitar aos estudantes a apropriação dos conhecimentos e

Rev. Diálogo Educ., Curitiba, v. 10, n. 29, p. 205-229, jan./abr. 2010 
das experiências histórico-culturais da humanidade. Entretanto, dada a vastíssima experiência da humanidade, mais importante do que ensinar todo e qualquer conhecimento, o que seria tarefa impossível, é ensinar ao estudante um modo de ação generalizado de acesso, utilização e criação do conhecimento, o que se torna possível ao considerar-se a formação do pensamento teórico. Nesse movimento, a qualidade de mediação da Atividade Orientadora de Ensino se evidencia ao possibilitar que o sujeito singular aproprie-se da experiência humana genérica. Ou seja, a AOE configura-se como particular na relação entre o humano singular e o humano genérico no contexto escolar.

A Figura 1 a seguir, proposta originalmente por Moraes (2008, p.116), sintetiza os componentes centrais da Atividade Orientadora de Ensino, a relação entre atividade de ensino, atividade de aprendizagem e os elementos estruturantes da atividade.

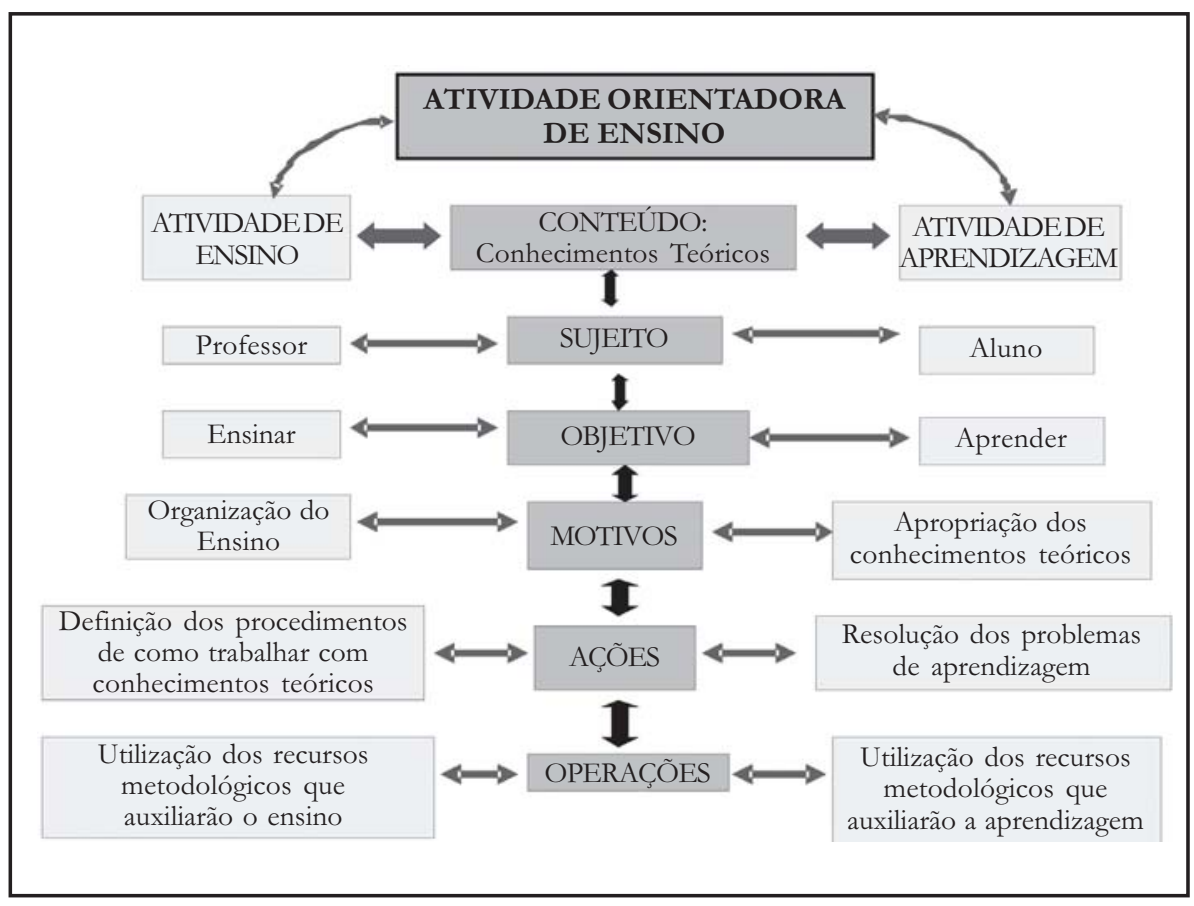

FIGURA 1 - AOE: relação entre atividade de ensino e atividade de aprendizagem

Rev. Diálogo Educ., Curitiba, v. 10, n. 29, p. 205-229, jan./abr. 2010 
O ensino tomado como atividade, como o concebe Leontiev com um caráter de processo social, mediado por instrumentos e signos, e estruturado a partir de uma necessidade - exige um modo especial de organização. A qualidade de atividade ao ensino dá-se pela necessidade de proporcionar a apropriação da cultura que pode mobilizar os sujeitos a agirem para a concretização de um objetivo comum: o desenvolvimento das potencialidades humanas para a apropriação e desenvolvimento de bens culturais (linguagem, objetos, ferramentas e modo de ação). É esse modo especial de organizar o ensino em que objetivos, ações e operações se articulam como atividade que dá à Atividade Orientadora de Ensino a dimensão de unidade formadora do aluno e do professor ao concretizarem a apropriação da cultura no contexto da educação escolar. Assim, a qualidade de mediação da AOE a caracteriza como um ato intencional, o que imprime uma responsabilidade ímpar aos responsáveis pela educação escolar. Esta, entende-se, é primordialmente a responsável pela aprendizagem de conceitos científicos e o desenvolvimento do pensamento teórico, orientada pela intencionalidade de impactar os sujeitos, proporcionando as alterações no desenvolvimento de suas funções psíquicas e a apropriação de conceitos científicos.

No âmbito das diversas pesquisas ancoradas no conceito de Atividade Orientadora de Ensino desenvolvidas por pesquisadores que trabalham com essa perspectiva teórica para a organização do ensino, duas vertentes vêm se configurando: a utilização do conceito para a organização da atividade pedagógica e como instrumento metodológico de pesquisas sobre o ensino, ou seja, a AOE vem sendo explorada como fonte de pesquisa e como fundamento para o ensino (ARAUJO, 2003; CEDRO, 2004; LOPES, 2004; MORAES, 2008; MORETTI, 2007; SERRÃO, 2006).

Os elementos característicos da Atividade Orientadora de Ensino (necessidades, motivos, ações, operações) permitem que ela seja elemento de mediação entre a atividade de ensino e a atividade de aprendizagem. Logo, a atividade de ensino e a atividade de aprendizagem só podem ser separadas para fins de explicação didática, entretanto, o motivo de ambas deve coincidir para que sejam concretizadas. Tal motivo é a apropriação pelos estudantes da experiência histórica acumulada, pela via do pensamento teórico e dos conceitos científicos, visando ao desenvolvimento do psiquismo, das funções psíquicas superiores. Não há sentido na atividade de ensino se ela não se concretiza na atividade de aprendizagem, por sua vez, não existe a

Rev. Diálogo Educ., Curitiba, v. 10, n. 29, p. 205-229, jan./abr. 2010 
atividade de aprendizagem intencional se ela não se dá de forma consciente e organizada por meio da atividade de ensino.

Nesse sentido, reafirmamos que a Atividade Orientadora de Ensino é a mediação na atividade do professor que tem como necessidade o ensino de um conteúdo ao sujeito em atividade cujo objetivo é a apropriação desse conteúdo entendido como um objetivo social. Nessa perspectiva, a AOE constitui-se em um modo geral de organização do ensino, em que seu conteúdo principal é o conhecimento teórico e seu objeto é a constituição do pensamento teórico do indivíduo no movimento de apropriação do conhecimento. Assim, o professor, ao organizar as ações que objetivam o ensinar, também requalifica seus conhecimentos, e é esse processo que caracteriza a AOE como unidade de formação do professor e do estudante (MOURA, 1996, 2001).

O conceito de Atividade Orientadora de Ensino como fundamento para o ensino é dinâmico. Não é um objeto, mas sim um processo e como tal é voltado à apropriação dos conhecimentos teóricos que explicam a realidade em movimento conforme seus personagens e relações, constituindo-se de forma dialética na relação entre o ideal e o real e enquanto processo de ação e reflexão. A atividade é orientadora no sentido em que é construída na inter-relação professor e estudante e está relacionada à reflexão do professor que durante todo o processo sente necessidade de reorganizar suas ações por meio da contínua avaliação que realiza acerca da coincidência ou não entre os resultados atingidos por suas ações e os objetivos propostos.

Esse modo de conceber o ensino pressupõe também que seja gerada nos estudantes a necessidade de se apropriar de conceitos, o que se concretiza na situação desencadeadora da aprendizagem. O objetivo principal desta é proporcionar a necessidade de apropriação do conceito pelo estudante, de modo que suas ações sejam realizadas na busca da solução de um problema que o mobilize para atividade de aprendizagem - a apropriação dos conhecimentos.

Retomando a estrutura da Atividade, temos que o sujeito em atividade tem objetivos ideais (individuais e coletivos), define ações para atingi-los e, conforme as condições reais, executa as operações (outro dos elementos estruturadores da atividade) que sustentam as ações. Desse processo deriva o produto da atividade que pode ser real ou ideal. No caso de professor e estudante incluem-se entre as ações e operações, as leituras, os estudos teóricos e práticos, reuniões, os registros individuais e coletivos,

Rev. Diálogo Educ., Curitiba, v. 10, n. 29, p. 205-229, jan./abr. 2010 
as discussões em grupos, a elaboração de planos de aula, a escolha de instrumentos metodológicos, entre outros.

Isoladamente, as ações não garantem a satisfação de uma necessidade, mas compõem e estruturam a atividade e, desta forma, adquirem sentido. $\mathrm{O}$ estudante que toma parte da atividade ao realizar as ações pode estar mobilizando apenas motivos compreensíveis. Estes, segundo Leontiev (1978), conferem um sentido pessoal à atividade e aos fins das ações. Ainda segundo o autor, são os motivos eficazes que têm uma função impulsionadora da atividade. No caso de uma atividade de aprendizagem são os motivos eficazes que possibilitam ao aluno estabelecer uma relação entre o motivo objetivo da atividade e a ação desenvolvida para aprender. Se não for assim, suas ações serão vazias de sentido para si.

De forma mais específica, podemos entender como ações do professor em atividade de ensino eleger e estudar os conceitos a serem apropriados pelos estudantes; organizá-los e recriá-los para que possam ser apropriados; organizar o grupo de estudantes de modo que as ações individuais sejam providas de significado social e sentido pessoal na divisão de trabalho do coletivo; e refletir sobre a eficiência das ações se realmente conduziu aos resultados inicialmente idealizados.

$\mathrm{Na}$ Atividade Orientadora de Ensino as necessidades, motivos, objetivos, ações e operações do professor e dos estudantes se mobilizam inicialmente por meio da situação desencadeadora de aprendizagem. Esta é organizada pelo professor a partir dos seus objetivos de ensino que, como dissemos, se traduzem em conteúdos a serem apropriados pelos estudantes no espaço de aprendizagem. As ações do professor serão organizadas inicialmente visando colocar em movimento a construção da solução da situação desencadeadora de aprendizagem. Essas ações, por sua vez, ao serem desencadeadas, considerarão as condições objetivas para o desenvolvimento da atividade: as condições materiais que permitem a escolha dos recursos metodológicos, os sujeitos cognoscentes, a complexidade do conteúdo em estudo e o contexto cultural que emoldura os sujeitos e permite as interações sócio-afetivas no desenvolvimento das ações que visam o objetivo da atividade - a apropriação de certo conteúdo e do modo geral de ação de aprendizagem.

Em outras palavras, os sujeitos, mobilizados a partir da situação desencadeadora, interagem com os outros segundo as suas potencialidades e visam chegar a outro nível de compreensão do conceito em movimento. Além disso, o modo de ir se aproximando do conceito também vai

Rev. Diálogo Educ., Curitiba, v. 10, n. 29, p. 205-229, jan./abr. 2010 
dotando-o de uma qualidade nova ao ter que resolver problemas, pois, além de ter aprendido um conteúdo novo, também adquiriu um modo de se apropriar de conteúdos de um modo geral.

A situação desencadeadora de aprendizagem deve contemplar a gênese do conceito, ou seja, a sua essência; ela deve explicitar a necessidade que levou a humanidade à construção do referido conceito, como foram aparecendo os problemas e as necessidades humanas em determinada atividade e como os homens foram elaborando as soluções ou sínteses no seu movimento lógico-histórico. Conforme Kopnin "para revelar a essência do objeto é necessário reproduzir o processo histórico real de seu desenvolvimento, mas este é possível somente se conhecemos a essência do objeto" (KOPNIN, 1978, p. 184). Para romper tal círculo, o autor considera que o estudo do objeto deve ser iniciado pelo seu fim, por sua forma que contenha os aspectos essenciais suficientemente desenvolvidos. Neste estudo, por meio das abstrações autênticas, características do pensamento teórico é que se capta a essência do objeto ou fenômeno, suas definições primárias e abstratas e se descobre a história deste fenômeno. Tratase da unidade do histórico e do lógico como premissa para compreender a essência de um objeto, de um conceito, sua estrutura, sua história, seu desenvolvimento. Nessa perspectiva, "educar seria proporcionar ao aluno um encontro pedagógico com os conceitos; a formação de uma visão de transformação e de movimento contínuo da realidade humana" (SOUSA, 2009, p. 88).

Entende-se também que há a preocupação com a compreensão do surgimento de um conceito, mas também com as suas formas de apropriação pela humanidade. Desta forma, segundo a nossa interpretação dos pressupostos de Kopnin sobre o modo como podemos conhecer o objeto, é que entendemos que a Atividade Orientadora de Ensino visa centralmente um problema de aprendizagem, e não um problema prático. A distinção desses dois tipos de problemas foi feita por Rubtsov (1996), o qual afirma que um problema concreto prático busca modos de ação em si, a aquisição de uma ação para a resolução de uma situação específica particular; já num problema de aprendizagem, o estudante se apropria de uma forma de ação geral, que se torna base de orientação das ações em diferentes situações que o cercam.

As situações desencadeadoras de aprendizagem podem ser materializadas por meio de diferentes recursos metodológicos. Dentre

Rev. Diálogo Educ., Curitiba, v. 10, n. 29, p. 205-229, jan./abr. 2010 
esses recursos, Moura e Lanner de Moura (1998) destacaram em seus estudos o jogo, as situações emergentes do cotidiano e o que chamam de história virtual do conceito. Esta última é compreendida como uma narrativa que proporciona ao aluno envolver-se na solução de um problema como se fosse parte de um coletivo que busca solucioná-lo, tendo como fim a satisfação de uma determinada necessidade à semelhança do que pode ter acontecido em certo momento histórico da humanidade. Para os autores, o significado de virtual encontra-se ao apresentar um problema na situação desencadeadora de aprendizagem que possua todas as condições essenciais do conceito vivenciado historicamente pela humanidade.

Os autores defendem que tal organização do ensino cria condições para que os estudantes entrem em atividade. Segundo eles,

o jogo com propósito pedagógico pode ser um importante aliado no ensino, já que preserva o caráter de problema. [...] O que devemos considerar é a possibilidade do jogo colocar a criança diante de uma situação-problema semelhante à vivenciada pelo homem ao lidar com conceitos matemáticos.

$[\cdots]$

A problematização de situações emergentes do cotidiano possibilita à prática educativa oportunidade de colocar a criança diante da necessidade de vivenciar solução de problemas significativos para ela.

$[\ldots]$

É a história virtual do conceito porque coloca a criança diante de uma situação problema semelhante àquela vivida pelo o homem (no sentido genérico) (MOURA; LANNER DE MOURA, 1998, p. 12-14).

Dado que a atividade de ensino, mediada pela AOE, deve oferecer condições para que os estudantes realizem ações de aprendizagem, a avaliação constitui-se parte inerente do planejamento e da realização da atividade, tendo em vista que essa se concretiza no processo de análise e síntese na relação entre a atividade de ensino do professor e a atividade de aprendizagem do estudante. As ações de aprendizagem realizadas pelos estudantes se constituirão como foco da

Rev. Diálogo Educ., Curitiba, v. 10, n. 29, p. 205-229, jan./abr. 2010 
análise do professor que, assim, poderá refletir sobre a qualidade da Atividade Orientadora de Ensino.

$\mathrm{Na}$ Atividade Orientadora de Ensino, a solução da situaçãoproblema pelos estudantes deve ser realizada na coletividade. Isso se dá quando aos indivíduos são proporcionadas situações que exijam o compartilhamento das ações na resolução de uma determinada situação que surge em certo contexto. Garantir que a atividade de estudo dos educandos se dê prioritariamente dentro de um coletivo, busca concretizar o princípio ou lei de formação das funções psíquicas superiores elaborado pela Teoria histórico-cultural em acordo com o que preconiza Vigotski ao afirmar que:

portanto, se pergunta de onde nascem, como se formam, de que modo se desenvolvem os processos superiores do pensamento infantil, devemos responder que surgem no processo de desenvolvimento social da criança, por meio da translação a si mesma de formas de colaboração que a criança assimila durante a interação com o meio social que a rodeia. Vemos que as formas coletivas de colaboração precedem às formas individuais da conduta, que crescem sobre a base das mesmas e constituem suas progenitoras diretas e as fontes de sua origem (VYGOTSKI, 1997, p. 219).

Neste sentido, o compartilhamento assume o significado da coordenação das ações individuais em determinada situação-problema comum aos indivíduos. Essa coordenação passa, portanto, pela identificação das características do objeto, pela sua transformação e pela criação de resultados em comum. Logo, o compartilhamento das ações "se manifesta em uma atividade cognitiva produtiva através de um nível elevado de estruturação da atividade intelectual, e num intensificado da reflexão, do controle e da avaliação" (POLIVANOVA, 1996, p. 151).

De acordo com os pressupostos da AOE, na relação entre ensino e aprendizagem, a cultura aparece como algo a ser apropriado e interiorizado pelos indivíduos. Segundo Davidov (1988), a interiorização constitui-se na transformação da atividade coletiva (experiência social) em uma atividade individual (experiência do indivíduo). Essa transformação é possível por meio da comunicação

Rev. Diálogo Educ., Curitiba, v. 10, n. 29, p. 205-229, jan./abr. 2010 
entre as pessoas. Nesse sentido, tem-se que a relação entre atividade coletiva e individual está relacionada com a tese vigotskiana de que o conhecimento ocorre em um primeiro momento no social (interpessoal) para transformar em individual (intrapessoal). Nesse mesmo sentido, contribui significativamente Rubtsov (1996), ao defender que a aptidão para a aprendizagem é fruto de uma determinada interiorização, originada essencialmente de situações de atividade coletiva. Essa transformação, do social para o individual, não é imediata, ao contrário, constitui-se em um longo processo de desenvolvimento. Vigotski (2002, p. 75) esclarece que "a internalização de formas culturais de comportamento envolve a reconstrução da atividade psicológica, tendo como base as operações com signos".

A Atividade Orientadora de Ensino, planejada e desenvolvida sobre as bases dos elementos da Atividade (necessidade, motivos, objetivos, ações e operações), sendo mediação conduz ao desenvolvimento do psiquismo dos sujeitos que a realizam. O processo de elaboração e concretização da Atividade Orientadora de Ensino, enquanto mediadora, na dimensão teórica e prática, da atividade do professor e do estudante desencadeia assim:

- A formação do estudante, que ao ser sujeito na atividade de aprendizagem se apropria do conhecimento teórico, desenvolvendo-se, transformando-se, humanizando-se, no movimento de análise e síntese inerente ao processo de solução do problema de aprendizagem da AOE;

- A formação do professor, que tem por objetivo ensinar o aluno e que, entretanto, nas discussões coletivas, no movimento dos motivos de sua atividade, das ações, operações e reflexões que realiza, aprende a ser professor aproximando o sentido pessoal de suas ações da significação da atividade pedagógica como concretizadora de um objetivo social.

Os fundamentos teórico-metodológicos da AOE, cujos pressupostos estão ancorados na teoria histórico-cultural e na teoria da atividade, são indicadores de um modo de organização do ensino para que a escola cumpra sua função principal, que é possibilitar a apropriação dos conhecimentos teóricos pelos estudantes. Assim, a AOE, enquanto mediação, é instrumento do professor para realizar e compreender seu

Rev. Diálogo Educ., Curitiba, v. 10, n. 29, p. 205-229, jan./abr. 2010 
objeto de estudo: o processo de ensino de conceitos. E é instrumento do estudante que por meio dela pode apropriar-se de conhecimentos teóricos. Desse modo, a AOE tem as características de fundamento para o ensino e é também fonte de pesquisa sobre o ensino. Assim, profissionais pesquisadores podem usar sua estrutura para identificar motivos, necessidades, ações desencadeadas e sentidos atribuídos pelos sujeitos no processo de ensino.

\section{REFERÊNCIAS}

ARAUJO, E. S. Da formação e do formar-se: a atividade de aprendizagem docente em uma escola pública. 2003. Tese (Doutorado em Educação) Faculdade de Educação, Universidade de São Paulo, São Paulo, 2003.

BOGOYAVLENSKY, D. N.; MENCHINSKAYA, N. A. Relação entre aprendizagem e desenvolvimento psicointelectual da criança em idade escolar. In: LEONTIEV, A. et al. Psicologia e pedagogia I: bases psicológicas da aprendizagem e do desenvolvimento. São Paulo. Centauro: 2003. p. 37-58.

CEDRO, W. L. O espaço de aprendizagem e a atividade ensino: o clube de Matemática. 2004. Dissertação (Mestrado em Educação) - Faculdade de Educação, Universidade de São Paulo, São Paulo, 2004.

DAVIDOV, V.; MARKOVA, A. La concepcion de la actividad de estudio de los escolares. In: DAVIDOV, V.; SHUARE, M. La psicología evolutiva y pedagógica en la URSS: antología. Moscú: Editorial Progreso, 1987. p. 316336.

DAVYDOV, V. Tipos de generalizacion en la ensenanza. Havana: Pueblo y Educacion, 1982.

La ensenanza escolar y el desarrollo psíquico. Moscou: Progreso, 1988.

ITELSON, L. B. Esencia del aprendizaje y bases psicologicas de la ensenanza. In: PetrovsKy, A. V. Psicologia evolutiva e pedagógica. Moscou: Progresso, 1979, p. 205-240.

KOPNIN, P. V. A dialética como lógica e teoria do conhecimento. Rio de Janeiro: Civilização Brasileira, 1978. (Coleção Perspectivas do homem).

Rev. Diálogo Educ., Curitiba, v. 10, n. 29, p. 205-229, jan./abr. 2010 
KUZMINA, N. Ensayo sobre la psicologia de la actividad del maestro. Tradução de Rosário Bilbao Crespo. Habana: Editorial Pueblo y Educación, 1987.

LEONTIEV, A. O desenvolvimento do psiquismo. São Paulo: Moraes, 1978.

Actividad, conciencia, personalidad. 2. ed. Havana: Pueblo y Educacion, 1983.

Uma contribuição à teoria do desenvolvimento da psique infantil. In: VIGOTSKI, L. S.; LURIA, A. R.; LEONTIEV, A. N. Linguagem, desenvolvimento e aprendizagem. 5. ed. São Paulo: Ícone, 1994.

LOPES, A. R. L. V. A aprendizagem docente no estágio compartilhado. 2004. Tese (Doutorado em Educação) - Faculdade de Educação, Universidade de São Paulo, São Paulo, 2004.

MARX, K.; ENGELS, F. A ideologia alemã. São Paulo: Grijalbo, 1977.

MORAES, S. P. G. de. Avaliação do processo e ensino e aprendizagem em matemática: contribuições da teoria histórico-cultural. 2008. Tese (Doutorado em Educação) - Faculdade de Educação, Universidade de São Paulo: São Paulo, 2008.

MORETTI, V. D. Professores de matemática em atividade de ensino: uma perspectiva histórico-cultural para a formação docente. 2007. Tese (Doutorado em Educação) - Faculdade de Educação, Universidade de São Paulo, São Paulo, 2007.

MOURA, M. O. de. (Coord.). Controle da variação de quantidades: atividades de ensino. São Paulo, Universidade de São Paulo, 1996.

A atividade de ensino como ação formadora. In: CASTRO, A. D.; CARVALHO, A. M. P. de. (Org.). Ensinar a ensinar: didática para a escola fundamental e média. São Paulo: Pioneira Thompson, 2002.

MOURA, M. O. de; LANNER de MOURA, A. R. Escola: um espaço cultural. Matemática na educação infantil: conhecer, (re)criar - um modo de lidar com as dimensões do mundo. São Paulo: Diadema/SECEL, 1998.

Rev. Diálogo Educ., Curitiba, v. 10, n. 29, p. 205-229, jan./abr. 2010 
POLIVANOVA, N. Particularidades da solução de um problema combinatório por estudantes em atuação de cooperação. In: GARNIER, C.; BeDnarz, N.; Ulanovskaya, I. Após Vygotsky e Piaget: perspectivas social e construtivista. escolas russa e ocidental. Porto Alegre: Artes Médicas, 1996. p. 151-159.

RUBTSOV, V. A atividade de aprendizado e os problemas referentes à formação do pensamento teórico dos escolares. In: GARNIER, C. et al. (Org.). Após Vygotsky e Piaget: perspectivas social e construtivista escolas russa e ocidental. Porto Alegre: Artes Médicas, 1996.

SERRÃO, M. I. B. Aprender a ensinar: a aprendizagem do ensino no curso de Pedagogia sob o enfoque histórico-cultural. São Paulo: Cortez, 2006.

SFORNI, M. S. Aprendizagem conceitual e organização do ensino: contribuições da Teoria da Atividade. Araraquara: JM, 2004.

SOUSA, M. C. Quando professores têm a oportunidade de elaborar atividades de ensino de matemática na perspectiva lógico-histórica. Bolema, Rio Claro, ano 22, n. 32, p. 83-99, 2009.

VIGOTSKI, L. S. Obras escogidas IV. Madrid: Visor, 1996.

Obras escogidas V. Madrid: Visor, 1997.

. A construção do pensamento e da linguagem. São Paulo: Martins Fontes, 2001.

A formação social da mente. 6. ed. São Paulo: Martins Fontes, 2002

Recebido: 04/09/2009

Received: 09/04/2009

Aprovado: 30/10/2009

Approved: 10/30/2009

Rev. Diálogo Educ., Curitiba, v. 10, n. 29, p. 205-229, jan./abr. 2010 